\title{
Knowledge, Attitude, and Practice (KAP) of Voluntary Blood Donation among Nurses in Mosul Teaching Hospital
}

\author{
Mahmoud Mohammed Ahmed * Ahmed Ali Hussein ** Nasir Mufaq Youns ***
}

\section{ABSTRACT}

Background and aim : blood can save millions of lives. The requirement of blood and blood products in a country depends on the population, health care structure, prevalence of conditions requiring regular transfusions, such as hemophilia and thalassemia etc., availability of surgical centers using modern sophisticated techniques, and awareness amongst clinicians regarding the judicious use of blood. The study aimed to assess of Knowledge, Attitude, and Practice (KAP) of Voluntary Blood Donation among nurses at the Mosul Teaching Hospital.

Materials and Method: Cross-sectional design was applied in this study that aimed to assessment of knowledge, Attitude, and practice of voluntary blood donation among nurses in Mosul Teaching Hospital. Random sample consists of (152) nurses (99) Male, (53) Female, and the sample age range (median age) 18-60 (26.3 \pm ) years. Data were collected from first December 2013 extended from First February 2014.Data were collected from all Mosul Teaching Hospital (Ibn-Sena Teaching Hospital, ALZahraweeTeahing Hospital, AL-Salm Teaching Hospital,Ibn-AtherTeahing Hospital and AlKhansaTeahing Hospital). An interview technique, method was used for data collection and data were analyzed as Frequency, percentage and Chi-Squire.

Results: The results of the study show that the Knowledge, Attitude, and Practice(KAP) of Voluntary Blood Donation among nurses in Mosul Teaching Hospital is good knowledge toward blood donation (81.4\%), positive attitude about (78.2\%),but there were practices of blood donation correct $(56.7 \%)$

Conclusion: The study concluded that the Nurses in hospitals have good knowledge of voluntary donation and a positive attitude towards donation, but there were disparities in their practices of blood donation.

Recommendation: The study recommended there is an urgent need to create and strengthen programs for motivation, recruitment and retention of voluntary blood Donors in our country.

Keywords:-Knowledge, Attitude, Practice, Nurses, Voluntary blood donation.

\section{INTRODUCTION}

Blood can save millions of lives. The requirement of blood and blood products in a country depends on the population, health care structure, prevalence of conditions requiring regular transfusions, such as haemophilia and thalassaemia etc., availability of surgical centers using modern sophisticated techniques, and awareness amongst clinicians regarding judicious use of blood. However problem regarding a permanent shortage of blood is observed in blood services all over the world(Sojka et al., 2003). The only source of blood is by blood donation (Olaiya, 2004). However, recruitment of voluntary, non-remunerated blood donors poses major challenges to transfusion services throughout the world(Misje et al,2010).As per World Health Organization (WHO) norms, $1 \%$ of the population is generally the minimum needed to meet the country's most basic requirements for blood (WHO, 2008).donating blood is an act that can save the lives of thousands of people worldwide because blood is an essential element of human life and there are no substitutes for it. In spite of extensive efforts and a number of blood donation programmes being organized worldwide, the availability of blood still remains short to meet the increased demand for it. World Health Organization advocates that 3-5\% of the population should donate blood every year, which would be the ideal rate for maintaining a country's stock of blood and blood products at acceptable level (Zago et. al, 2010). The collection of blood should only be from voluntary donors (low risk population), that is one of the four components of WHO's integral strategy to promote global safety and minimize risk associated with transfusion(WHO,2001). Unfortunately, $83 \%$ of the global population who are living in developing countries have access to only $40 \%$ of blood supplied, and this blood in

\footnotetext{
* Lecturer / College of Nursing / University of Mosul.

** Lecturer / College of Nursing / University of Mosul.

*** Lecturer / College of Nursing / University of Mosul
} 
$60 \%$ of cases is collected from paid or replacement blood donors rather than from voluntary non-remunerated low risk donors(Mitra et. al., 2001).In India there is a need of about 8 million units of blood every year, out of which only about one third are obtained from voluntary donors(Ghose and Basu, 1996).In spite of extensive promising research, a true substitute for blood and blood components may not be available for many years (Loweand Ferguson, 2003). Therefore, blood donation by humans will continue to be the major source for blood and blood components. There are no national data in Iraq on blood donor demand (WHO,2011). The task of recruiting voluntary blood donors remains one of the major challenges for any blood transfusion service (Dorothy et. al, 2008). The numbers of potential donors were often reduced due to the strict selection criteria which were imposed to ensure the safety of the blood supplies. In addition to this, the blood centres find it difficult to recruit new donors and to retain them for arranging a regular blood supply for needy people. Consequently, the blood services need to organize more frequent blood drives to maintain a regular blood supply and to adopt an approach for enhancing new blood donor recruitment and retention of the donors (Ministry of Health and Family Welfare, India, 2003).One of the objectives of the National Blood Policy is to encourage research and development in the field of Transfusion Medicine. One of its strategies is to take the appropriate decision and/or to introduce policy initiatives on the basis of the factual information, the operational research on various aspects such as transfusion transmissible diseases, the Knowledge, Attitude and Practice (KAP) among donors, the clinical use of blood, etc (WHO, 2008). The aim of the study is to assess of knowledge, attitude, and practice (KAP) of voluntary blood donation among nurses in Mosul Teaching Hospital.

\section{MATERIALS AND METHOD:-}

Cross-sectional design was applied in this study that aimed to assessment of knowledge, Attitude, and practice of voluntary blood donation among nurses in Mosul Teaching Hospitals. Random sample consists of (152) nurses (99) Male, (53) Female, and the sample age range (median age) 18-60 (26.3 \pm ) years. Period of data collection extended from $1^{\text {st }}$ December 2013 to $1^{\text {st }}$ February 2014. Data were collected from all Mosul Teaching hospitals (IbnSena Teaching Hospital, AL-Zahrawee Teaching Hospital, AL-Salm Teaching Hospital, Ibn-AL Ather Teaching Hospital and AL-KhansaTeahing Hospital). Questionnaire tool was used, data collection consisting of Four parts, Part one: This part included (6) items which focus on the nurses' demographic characteristics such as (age, sex, marital status, Level of education, experience and work setting). Part two: Knowledge of blood transfusion contains (8) items. Part three: Attitude towards blood donation. It consists of (5) items. Part four: Practice of blood donation included (6) items. An interview method was used for data collection. Data were analyzed as Frequency, percentage and Chi-Squire to calculate the score of true answer.

\section{RESULTS}

Table (1) Demographic Characteristics of the Study Sample ( $N=152)$

\begin{tabular}{|c|c|c|}
\hline Variables & No. & Percentage $(\%)$ \\
\hline \multicolumn{3}{|l|}{ (A) Gender } \\
\hline Male & 99 & 65.1 \\
\hline Female & 53 & 34.9 \\
\hline Total & 152 & $100 \%$ \\
\hline \multicolumn{3}{|l|}{ (B) Age } \\
\hline$<20$ years & 6 & 3.9 \\
\hline $21-29$ years & 71 & 46.7 \\
\hline $30-39$ years & 52 & 34.2 \\
\hline 40-49 years & 13 & 8.6 \\
\hline 50 years or more & 10 & 6.6 \\
\hline Total & 152 & $100 \%$ \\
\hline \multicolumn{3}{|l|}{ (C) Marital status } \\
\hline Married & 108 & 71.1 \\
\hline Single & 42 & 27.6 \\
\hline Widowed & 2 & 1.3 \\
\hline Total & 152 & $100 \%$ \\
\hline
\end{tabular}




\begin{tabular}{|c|c|c|}
\hline \multicolumn{3}{|c|}{\begin{tabular}{|l|} 
(D) Educational level \\
\end{tabular}} \\
\hline Training course & 6 & 3.9 \\
\hline Secondary & 44 & 28.9 \\
\hline Institution & 48 & 31.6 \\
\hline College & 54 & 35.6 \\
\hline Total & 152 & $100 \%$ \\
\hline \multicolumn{3}{|l|}{ (E) Experience } \\
\hline $1-5$ years & 80 & 52.6 \\
\hline $6-10$ years & 42 & 27.6 \\
\hline $11-15$ years & 11 & 7.2 \\
\hline $16-20$ years & 4 & 2.6 \\
\hline More than 20 years & 15 & 9.9 \\
\hline Total & 152 & $100 \%$ \\
\hline \multicolumn{3}{|l|}{ (F) Work setting } \\
\hline Emergency & 26 & 17.1 \\
\hline Ward & 76 & 50.0 \\
\hline Operation unit & 29 & 19.1 \\
\hline Intensive unit & 21 & 13.8 \\
\hline Total & 152 & $100 \%$ \\
\hline \multicolumn{3}{|l|}{ (G) Hospitals } \\
\hline IBN-Sena & 35 & 23.03 \\
\hline AL-Zahrawee & 32 & 21.06 \\
\hline AL-Salm & 30 & 19.73 \\
\hline Ibn-Al Ather & 27 & 17.76 \\
\hline AL-khansa & 28 & 18.42 \\
\hline Total & 152 & $100 \%$ \\
\hline
\end{tabular}

Figure (1) :- Distribution of the nurses knowledge towards blood Donation.

Good Knowledge

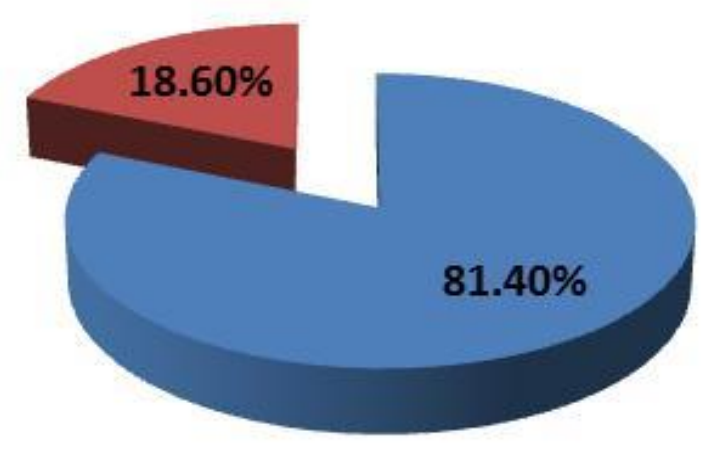

Poor Knowledge 
Table (2):Knowledge on Blood Donation $\mathrm{N}=152 \%$

\begin{tabular}{|c|c|}
\hline \multicolumn{2}{|c|}{ Do you know the common blood group? } \\
\hline Yes & $146(96.1 \%)$ \\
\hline No & $6(3.6 \%)$ \\
\hline \multicolumn{2}{|l|}{ Do you know your blood group? } \\
\hline Yes & $150(98.7 \%)$ \\
\hline No & $2(1.3 \%)$ \\
\hline \multicolumn{2}{|l|}{ Blood group of respondent? } \\
\hline A & $36(23.7 \%)$ \\
\hline B & $36(23.7 \%)$ \\
\hline $\mathrm{AB}$ & $19(12.5)$ \\
\hline $\mathrm{O}$ & $40(26.3)$ \\
\hline Don't know & $21(13.8)$ \\
\hline \multicolumn{2}{|c|}{ Can a person be infected by receiving blood transfusion? } \\
\hline Yes ( correct) & $150(98.7 \%)$ \\
\hline No(incorrect) & $2(1.3 \%)$ \\
\hline \multicolumn{2}{|c|}{ What diseases are transmissible by blood transfusion? } \\
\hline HIV & $122(80.3 \%)$ \\
\hline HBV & $135(88.8 \%)$ \\
\hline $\mathrm{HCV}$ & $120(78.9 \%)$ \\
\hline Syphilis & $50(32.9 \%)$ \\
\hline Malaria & $70(46.1 \%)$ \\
\hline \multicolumn{2}{|c|}{ How often can an individual donate? } \\
\hline Monthly & $20(13.2 \%)$ \\
\hline 3 Monthly & $52(34.2 \%)$ \\
\hline 6 Monthly & $57(37.5 \%)$ \\
\hline Annually & $6(3.9 \%)$ \\
\hline Don't know & $17(11.2 \%)$ \\
\hline \multicolumn{2}{|l|}{ Who should donate blood? } \\
\hline Men (correct) & $125(82.2 \%)$ \\
\hline Woman (correct) & $86(56.6 \%)$ \\
\hline Young $(<18$ years)(incorrect) & $26(17.1 \%)$ \\
\hline Old(>60 years)(incorrect) & $5(3.3 \%)$ \\
\hline Weight less than $50 \mathrm{~kg}$ (incorrect) & $19(12.5 \%)$ \\
\hline Healthy(correct) & $132(86.8 \%)$ \\
\hline Diseased (incorrect) & $2(1.3 \%)$ \\
\hline \multicolumn{2}{|c|}{ What volume of blood is collected duration each donation? } \\
\hline$\leq 500 \mathrm{mls}$ (correct) & $94(61.8 \%)$ \\
\hline $500-1000 \mathrm{mls}$ (incorrect) & $27(17.8 \%)$ \\
\hline Don't know & $31(20.4 \%)$ \\
\hline \multicolumn{2}{|c|}{ What is the duration of a donation Process? } \\
\hline$<20$ minutes & $75(49.3 \%)$ \\
\hline 20-60 minutes & $59(38.8 \%)$ \\
\hline Don't know & $18(11.8 \%)$ \\
\hline
\end{tabular}


Figure (2):- Distribution of the nurses attitude toward blood donation.

Positive Attitude

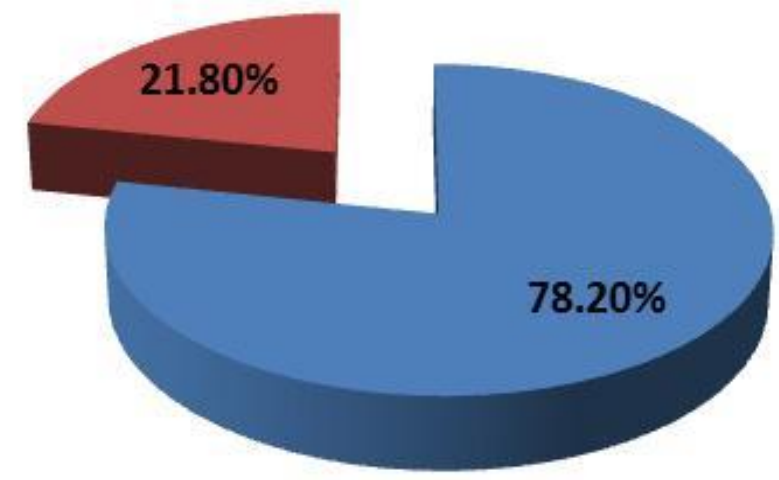

Negative Attitude

Table (3):Attitude of Blood Donation

\begin{tabular}{||l|c|}
\hline What do you think about blood donation? & $\mathbf{N}(\%)$ \\
\hline Good & $117(77.0 \%)$ \\
\hline Bad & $4(2.6 \%)$ \\
\hline Neutral & $31(20.4 \%)$ \\
\hline What do you think is the best source of blood donors? \\
\hline Voluntary donor & $130(85.5 \%)$ \\
\hline Replacement donor & $5(3.3 \%)$ \\
\hline Remunerated donor & $2(1.3 \%)$ \\
\hline Self-donor & $15(9.9 \%)$ \\
\hline Can something harmful happened to blood donor during or after donation? \\
\hline Yes & $111(73.0 \%)$ \\
\hline No & $22(14.5 \%)$ \\
\hline I don't know & $19(12.5 \%)$ \\
\hline What can be happened to the blood donor during or after donation? \\
\hline Contract Infection & $12(7.9 \%)$ \\
\hline Temporary Weakness & $136(89.5 \%)$ \\
\hline Fall sick & $4(2.6 \%)$ \\
\hline Should patient relatives be asked to donate? & $119(78.3 \%)$ \\
\hline Yes & $23(15.1 \%)$ \\
\hline No & $10(6.6 \%)$ \\
\hline I don't know & \\
\hline
\end{tabular}


Figure (3):- Distribution of the nurses answer toward practice question about blood donation

Correct

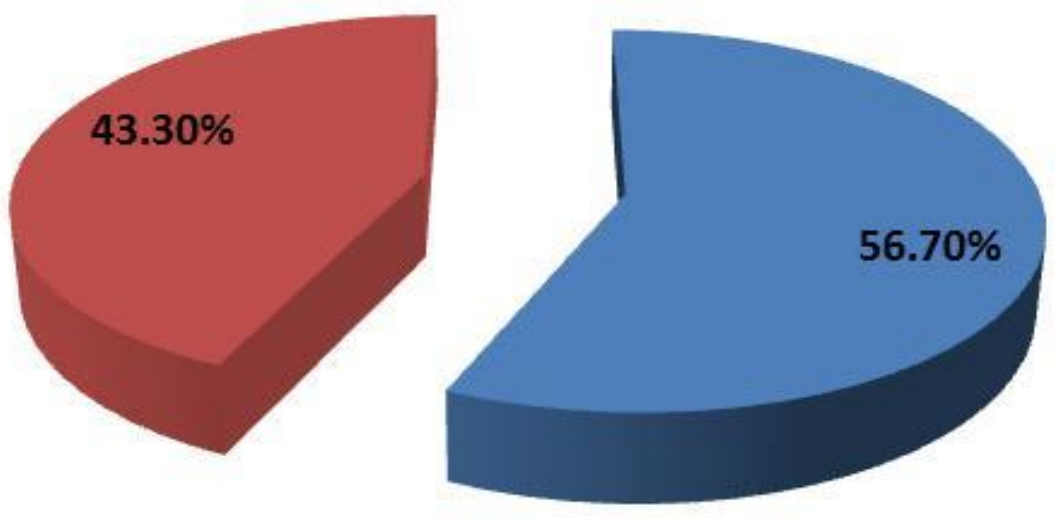

Incorrect

Table (4):Practice of Blood Donation ( $\mathrm{N}=152$ )

\begin{tabular}{||l|c|}
\hline Have you donated before ? & $53(34.9 \%)$ \\
\hline Yes & $99(65.1 \%)$ \\
\hline No & $23(43.4 \%)$ \\
\hline How often do you donate? & $25(47.2 \%)$ \\
\hline 1 time < a year & $5(9.4 \%)$ \\
\hline $1-3$ times a year & \\
\hline$>3$ times a year & $18(34.0 \%)$ \\
\hline Why did you donate ? & $33(62.3 \%)$ \\
\hline A friend or relative needed blood & $1(1.9 \%)$ \\
\hline Voluntary & $1(1.9 \%)$ \\
\hline Remuneration & $120(78.9 \%)$ \\
\hline To know my screening status & $32(21.1 \%)$ \\
\hline Will you donate if called upon or reminded to do so? & \\
\hline Yes & $41(77.4 \%)$ \\
\hline No & $12(22.6 \%)$ \\
\hline Number of those who stated their contact? & \\
\hline Yes & $70(46.1 \%)$ \\
\hline No & $30(19.7 \%)$ \\
\hline Reasons for non-donation by no donors? & $29(19.1 \%)$ \\
\hline Not approached to donate & $5(3.3 \%)$ \\
\hline Unfit to donate & $13(8.6 \%)$ \\
\hline Need to donate for friends or relatives in future & $4(2.6 \%)$ \\
\hline Fear of needles & $1(0.7 \%)$ \\
\hline Fear of knowing my status & $120(78.9 \%)$ \\
\hline Donated blood may be sold & $32(21.1 \%)$ \\
\hline No remuneration & \\
\hline Do you encourage relatives to donate ? & \\
\hline Yes & \\
\hline No & \\
\hline
\end{tabular}


Table (5): The Association between Gender and Blood Donation.

\begin{tabular}{|c|c|c|c|}
\hline Gender & Donors(\%) & Non-donors(\%) & Total \\
\hline \hline Male & $50(94.33 \%)$ & $49(49.5 \%)$ & 99 \\
\hline Female & $3(5.67 \%)$ & $50(50.5 \%)$ & 53 \\
\hline Total & $53(100 \%)$ & $99(100 \%)$ & $152(100 \%)$ \\
\hline$\chi^{2}$ crit. $=\mathbf{3 0 . 5 6}$ & $\mathbf{P} \leq \mathbf{0 . 0 5}$ & df $=\mathbf{1}$ & $\boldsymbol{\chi}^{\mathbf{2}}$ obs. $=\mathbf{3 . 8 4}$ Sig. \\
\hline
\end{tabular}

This table indicated that the man were blood donation more than women.

Table (6): Distributions of Sample According their Experience.

\begin{tabular}{|l|c|c|c|}
\hline \multicolumn{1}{|c|}{ Experience } & Donors(\%) & Non-donors(\%) & Total \\
\hline \hline 1-5 years & $2(3.77 \%)$ & $4(4.04 \%)$ & 6 \\
\hline 6-10 years & $11(20.76 \%)$ & $60(60.6 \%)$ & 71 \\
\hline 11-15 years & $30(56.6 \%)$ & $22(22.22 \%)$ & 52 \\
\hline 16-20 years & $4(7.54 \%)$ & $9(9.1 \%)$ & 13 \\
\hline More than 20 years & $6(11.33 \%)$ & $4(4.04 \%)$ & 10 \\
\hline \multicolumn{1}{|c|}{ Total } & $53(100 \%)$ & $99(100 \%)$ & $152(100 \%)$ \\
\hline
\end{tabular}

Table (7): Distributions of sample according their level of education .

\begin{tabular}{|c|c|c|c|}
\hline Educational level & Donors(\%) & Non-donors(\%) & Total \\
\hline \hline Training course & $1(1.88 \%)$ & $5(5.06 \%)$ & 6 \\
\hline Secondary & $21(39.63 \%)$ & $23(23.23 \%)$ & 44 \\
\hline Institute & $21(39.63 \%)$ & $27(27.27 \%)$ & 48 \\
\hline College & $10(18.86 \%)$ & $44(44.44 \%)$ & 54 \\
\hline Total & $53(100 \%)$ & $99(100 \%)$ & $152(100 \%)$ \\
\hline
\end{tabular}

\section{DISCUSSION}

There are lots of publications assessing the knowledge, attitude, and practice of voluntary blood donation; however, very few studies have been published which assess the same on the healthcare workers in our environment and globally (Benedict et. al., 2013). The nurses who respondent in this study were (152) and (18-50 years or more) median age was $(26.3 \pm)$ years. Males in our society are more likely to donate blood than females approximately (65.1\%), and the majority of the study sample were married $(71.1 \%)$, while $(27.6 \%)$ were singles (Table 1 ). These studies found the majority of nurses with (1-5 years) experience approximately (52.6\%). Nurses worker in four departments, including ward $(50.0 \%)$, operational unit $(19.1 \%)$, emergency $(17.1 \%)$, and intensive unit (13.8\%). Their education level, most of the sample were college of nursing (35.5\%). Table (1). Figure (1) shows that there is the nurses knowledge toward blood donation is good knowledge (81.40\%). Table (2) knowledge of blood transfusion. A total of 152 respondents expressed good knowledge of the common blood group types. And 131(85.2\%) knew their own blood group. $\mathrm{A}(23.7 \%)$, B (23.7\%), $\mathrm{AB}(12,5 \%), \mathrm{O}(26.3 \%)$ and $(13.8 \%)$ did not know the blood group, (Table 2). The current study is in agreement with the study of (Benedict et.al, 2013) shown as expected that healthcare workers have a good knowledge of blood groups. Most respondents (91.3\%) were aware of the risk of transmission of infection by transfusion. The risk of transmission of HBV, HIV, HCV, Malaria and Syphilis (88.8\%), $(80.3 \%), \quad(78.9 \%), \quad(46.1 \%)$ and $(32.9 \%)$ respectively. In a similar study in Iran, (Reza et al., 2009) assessed the knowledge of 122 health care workers and found that $51.6 \%$ (just above average) have an acceptable knowledge on proper methods of blood and component transfusion. Fifty- seven (37.5\%) stated that the minimum interval between donation is 6 months , $52(34.2 \%)$ said 3 months, and 20(13.2\%) said a month, 6(3.9\%) said annually, while 17(11.2\%) they have no knowledge of this. With knowledge of the volume of blood collected at each donation, 94(61.8\%) stated less than $500 \mathrm{ml}$, $27(17.8 \%)$ ticked $500-1000 \mathrm{ml}$ while 31 (20.4\%) experts no knowledge of it.

Figure(2) show that there are the nurses attitude toward blood donation is a positive attitude $(78.20 \%)$. Table (3) Attitude towards blood donation. A hundred and seventeen 
(77.0\%) respondents said blood donation was good . Voluntary donation was accepted as the best source of blood donors by 130(85.5\%), replacement donors by $5(3.3 \%)$, remunerated by $2(1.3 \%)$ and self-donation by $15(9.9 \%)$.One hundred and thirty- six $(89.5 \%)$ said the donor may experience temporary weakness, and 12(7.9\%)said a donor can contact infection and $4(2.6 \%)$ said the donor may fall sick. One hundred and forty-two (93.4\%) feels that patient relative should be asked to donate, and 142 respondent have asked relatives in the past to donate. The results of my study are in agreement with the study of (Hossain et. al., 1997) Found that $(82 \%)$ of participants showed a positive attitude towards blood donation. In this study, we recorded (34.9\%) blood donated by nurses in the past with23(43.4\%) of them donating less than once a years, $25(47.2 \%$ ) between 1-3 times a years and $5(9.4 \%)$ more than thrice a years. This was a far cry from the knowledge and attitude indicated by the questionnaire. Voluntary blood donation among nurses though low generally, nurses in this study performed higher than their colleagues in the developed countries as documented in the studies by (Gilani et. al, 2007). Most (62.3\%)donated voluntary , (34.0\%) donated for friends and relatives (1.9\%), for remuneration. The reasons for non-donation by those who have not donated include no body approached them for donation 70 (46\%), unfit to donate $30(19.7 \%)$, need to donate for a friend or relative in future $29(19.1 \%)$, fear of knowing my status $13(8.6 \%)$,fear of needle $5(3.3 \%)$ the donated blood may be sold 4 (2.6\%)and no remuneration $1(0.7 \%)$. This study is in Disagreement with study that (Rajagopalan and Pulimood , 1998) Attitudes of medical and nursing students towards blood donation mention that Ninety percent of the respondents in this study intended to donate blood in future and they thought that fear (40.9\%), ignorance (31\%) and lack of motivations $(19.1 \%)$ were the main reasons for not donating blood by people. One hundred and twenty (78.9\%) encourage relatives to donate Table(4).Figure(3)show that there are the nurses disparities in their practices of blood donation about $(56.7 \%)$ have answer correct . This study found a significant association between blood donation and gender. The results are in agreement with the study of (Gillespie et al., 2002) The reasons for the less percentage of female donors could be a low donor turnover and temporary deferral conditions like low hemoglobin values, low weight, and fear of pain. In a study which was done by (Hollingsworth and
Wildman 2004), female donors constituted only $1 \%$ of the donor population (WHO) in report affirmation (2011) mention that the causes less female donation frequent menstrual cycles, pregnancy, and lactation. Table(5). Table (6) demonstrated the sample of the study according to their experience of nurses work that more ratio of blood donation between (1-6 years) about $(20.76 \%)$. Table (7) demonstrated the sample of the study according to their level of education more nurses of blood donation those obtaining the certificate of the Institute of Nursing approximately (39.63\%). There is need to properly harness this potential pool of donors if the drive for $100 \%$ voluntary donor targeted by the WHO will be achieved. For a sustainable blood banking system aimed at providing adequate and safe blood to all in need, a proper sensitization, and massive donor recruitment from all potential donors must be implemented.

\section{CONCLUSION}

The study concluded that the Nurses in hospitals have good knowledge of voluntary donation and a positive attitude towards donation but there were disparities in their practices of blood donation and the study elicits the importance of adopting effective measures in hospitals to motivate about voluntary blood donation among nurses.

\section{RECOMMENDATIONS}

There is an urgent need to create and strengthen programs for motivation, recruitment and retention of voluntary blood Donors in our country and implementation a larger study needs to be conducted with a wider pool of participants in order to gain more insights about nurses knowledge, attitudes and practices about blood donation.

\section{REFERENCES}

Benedict, N.; Usimenahon, A.; and Alexander, I. N. (2013). Knowledge, Attitude, and Practice of Voluntary Blood Donation among Healthcare Workers at the University of Benin Teaching Hospital, Benin City, Nigeria.79-30. 6 .

Dorothy DN, Deborah AD, Nora VH, Edward LM.(2008) Blood donor satisfaction and intention of future donation. Transfusion. 2008; 48:742-48.

Ghose, A.; and Basu, A. (1996). Blood. West Bengal: Voluntary Blood Donors Forum.

Gilani I, Kayani ZA; Atique, M.(2007). Knowledge, attitude and practices regarding blood donation prevalent in medical and 
paramedical personnel. J Coll Physicians Surg Pak. 17(8). P.p.473-6.

Gillespie, TW.; Hillyer, CD. (2002). Blood donors and factors impacting the blood donation decision. Transfusion medicine Reviews. 16. P.p.115-17.

Hollingsworth, B.; Wildman, J. (2004).What population influences the decision to donate blood?. Transfusion medicine. 14:9-12.

Hossain, GM.; Anisuzzaman, M.; Begum, A. (1997). Knowledge and attitude towards voluntary blood donation among Dhaka University students in Bangladesh. East Afr Med J. 74(9). P.p.549-553.

LoweK, C.; and Ferguson, E. (2003). "Benefit and risk perceptions transfusion medicine: blood and blood substitutes." Journal of Internal Medicine. 25(5). P.p. 498-507.

Misje, AH.; Bosnes, V.; Heier, HE. (2010). Gender differences in presentation rates, deferrals and return behavior among Norwegian blood donors. Vox Sang. 98. P.p.e241-248.

Mitra, K.; Mandal, P.K.; Nandy, S.; Roy, R.; Joardar, G.K.; Mishra, R.(2001). A study on awareness and perceptions regarding blood safety and blood donation among Health care providers in a Teaching Hospital of Calcutta. Ind $J$ of Comm Med. XXVI(1). P.p.21-26.

National Guidebook on Blood donor motivation. Ministry of Health and Family Welfare, National AIDS Control Organization, Government of India. Second edition 2003.
Olaiya MA, Ajala A, Olatunji RO (2004). Knowledge, attitudes, beliefs and motivations towards blooddonations among blood donors in Lagos, Nigeria. Transfusion Medicine. 14: 13-17.

Rajagopalan, M.; Pulimood, R. (1998). Attitudes of medical and nursing students towards blood donation. Natl Med J. 11(1). P.p.1213, .

Reza, P. A.; Aziz, S. V.; Ali, M. A.; Marjan, M. H.; and Reza, T. M. (2009). "Evaluation of knowledge of healthcare workers in hospitals of Zabol city on proper methods of blood and components transfusion,"Asian Journal of Transfusion Science. 3 (2).P.p. 78-81.

Sojka BN. (2003).The blood-donation experience: perceived physical, psychological and social impact of blood donation on the donor. Vox Sang. 84. P.p.120-128.

WHO Global Database on Blood Safety. (2011). "WHO report on Gender distribution of blood donors by country.

World Health Organization Blood Transfusion Safety. (2008). Available from: http://www. who.int/bloodsafety/voluntary donation/en/.

World Health Organization. (2011). Geneva. 3.

World Health Organization.(2001). The clinical use of blood-Handbook Geneva.

Zago, A.; Silveira, M.F.; Dumith, C.S. (2010). Blood donation prevalence and associated factors in Pelotas, Southern Brazil. Rev Saudi Publica. 44(1). P.p.112-120. 